\title{
Modified risk factors for presence of microalbuminuria in saudi adults with type I and type 2 diabetes mellitus
}

\begin{abstract}
Background: Diabetes is one of the most common chronic diseases. Diabetic nephropathy is one of the most serious chronic complications of type 1 and type 2 diabetes. We report on different risk factors between microalbuminuria presence in type 1 and type 2 diabetes patients attending a diabetes centre in Saudi Arabia.

Methods: The study was cross section conducted at the diabetes centre clinics at King Fahad Armed Forces Hospital, Jeddah, Saudi Arabia. A total of 296 Saudi with type 1 and type 2 diabetes associated with presence of microalbuminuria were randomly selected.

Results: Total of 296 patients with diabetes associated microalbuminuria were included in this study; $99(33.3 \%)$ with type 1 diabetes and $197(66.6 \%)$ with type 2 diabetes. $119(40.2 \%)$ were male and $177(59.8 \%)$ were female with mean age $35.0 \pm 8.4$ years. Significant female predominance (sex ratio male:female) $1: 2.3$ and $1: 1.2$ in type 1 diabetes with microalbuminuria and type 2 diabetes with microalbuminuria respectively $(\mathrm{p}=0.01)$. Hypertension was significantly more frequent in $131(72.0 \%)$ of type 2 diabetes with microalbuminuria compared to $51(28.0 \%)$ of type 1 diabetes with microalbuminuria $(\mathrm{p}=0.004)$ with significant difference between both gender. Type 2 diabetes with microalbuminuria have significant higher $\mathrm{HbA} 1 \mathrm{c}$ than patients with type 1 diabetes with microalbuminuria and there was a nonsignificant difference between gender and when compared to HbA1c groups. Male and Female with type 2 diabetes with microalbuminuria have nonsignificant $\mathrm{HbA1c}(\geq 7.0)$ than patients with Male and Female with type 1 diabetes with microalbuminuria.
\end{abstract}

Volume 5 Issue 4 - 2018

\author{
Khalid S Aljabri,' Samia A Bokhari,', Muneera \\ A Alshareef,' Patan M Khan,' Bandari K \\ Aljabri² \\ 'Department of Endocrinology, King Fahad Armed Forces \\ Hospital, Jeddah, Kingdom of Saudi Arabia \\ ${ }^{2}$ College of medicine, Um Al Qura University, Makkah, Kingdom \\ of Saudi Arabia
}

\begin{abstract}
Correspondence: Khalid S Aljabri, Department of Endocrinology, Jeddah, Kingdom of Saudi Arabia,Tel +966590008035, Email khalidsaljabri@yahoo.com
\end{abstract}

Received: April |4, 2018 | Published: August 14, 2018

\section{Introduction}

In both developed and developing countries, diabetes mellitus is common and result from both environmental etiological and genetic factors. ${ }^{1-3}$ Over $90 \%$ of diabetes is type 2 diabetes (T2DM) The natural history of diabetic nephropathy (DN) from prospective data is less well described for T2DM. ${ }^{4}$ The earliest clinical sign of DN, defined as microalbuminuria (MA) which is an elevated urinary excretion of albumin. MA is defined as an albumin excretion rate (AER) of 20-199 $\mathrm{g} / \mathrm{min}$ in a timed or a $24-\mathrm{hr}$ urine collection which is an equivalent to $30-299 \mathrm{mg} / \mathrm{g}$ creatinine in a random spot sample). ${ }^{5}$ The increased risk for renal and cardiovascular disease in T2DM is associated with the development of MA..$^{6-8}$ In many regions of the world, end-stage renal disease incidence in T2DM has risen. ${ }^{9-10}$ Diabetes is estimated to increase the risk of end-stage renal disease approximately 12 -fold and is also one of the predictor for cardiovascular disease. ${ }^{11,12-16}$ MA was found in $17-40 \%$ of patients with T2DM. ${ }^{17-22}$

Type 1 diabetes (T1DM) accounts for $7-12 \%$ of the total cases of diabetes and it is increasing globally by $3 \%$ each year. ${ }^{23} \mathrm{DN}$ is affecting approximately $20-30 \%$ of patients with T1DM and increasing the risk of cardiovascular disease and end-stage renal disease., ${ }^{5,24}$ The incidence of MA in T1DM individuals varies greatly among different populations. In T1DM, MA is found in $30-60 \%$ of patients. Parallel increase in the rate of complications, including $\mathrm{DN}$ will be in consistence with the global significant increase in incidence of T1DM and T2DM. The American Diabetes Association recommends annual screening for MA by means of a semiquantitative dipstick test which is considered to be easy, accurate and immediate. ${ }^{5,25}$ Although T1DM and T2DM is more common in Saudi Arabia than in Europeans in the $\mathrm{UK}$, very little is known about complications and their risk factors in Saudi Arabia. In this study we report on the difference in risk factors between MA presence in T1DM and T2DM patients attending a diabetes centre in Saudi Arabia.

\section{Methods}

A cross section study conducted at the diabetic centre Clinics at King Fahad Armed Forces Hospital. A total of 296 Saudi with diabetes were randomly selected. The medical history and demographic data were documented. Blood Pressure readings using a mercury sphygmomanometer by palpation and auscultation method in right arm in sitting position were measured within a gap of 15 minutes. Two readings, $15 \mathrm{~min}$ apart, were taken and the average of both the readings was recorded. Hypertension (HTN) was also diagnosed based on anti HTN medications were classified as Hypertensive irrespective of their current blood pressure reading or if the blood pressure was greater than 140/90 $\mathrm{mmHg}$ i,e systolic BP more than 140 and diastolic BP more than $90 \mathrm{~mm}$ of $\mathrm{Hg}$ according to the Report of the American College of Cardiology/American Heart Association Task Force on Clinical Practice Guidelines. ${ }^{26}$ Fasting serum lipids were measured on a sample of blood after fasting for 14 hours. 
We used the Enzmatic method for determining the cholesterol and triglycerides levels. The HbAlc was divided into three groups; $<7.0$, 7.0-9.0 and >9.0. MA was assessed by measurement of mean albumin excretion rate (AER) on timed, overnight urine collections. We use a polyclonal radioimmunoassay for albumin measurement. MA was defined as AER $30 \mathrm{~g} / \mathrm{min}$ in overnight urine collections (equivalent to $30-299 \mathrm{mg} / \mathrm{g}$ creatinine in a random spot sample).

\section{Statistical analysis}

Unpaired t-test was used to analyze univariate analysis of baseline and follow up demography and clinical laboratory endpoints. Categorical data comparison was accomplished using Chi square $\left(\mathrm{X}^{2}\right)$. All statistical analyses were performed using SPSS Version 22.0. All $\mathrm{P}$ values were based on two-sided tests. $\mathrm{P}<0.05$ was considered to be significant.

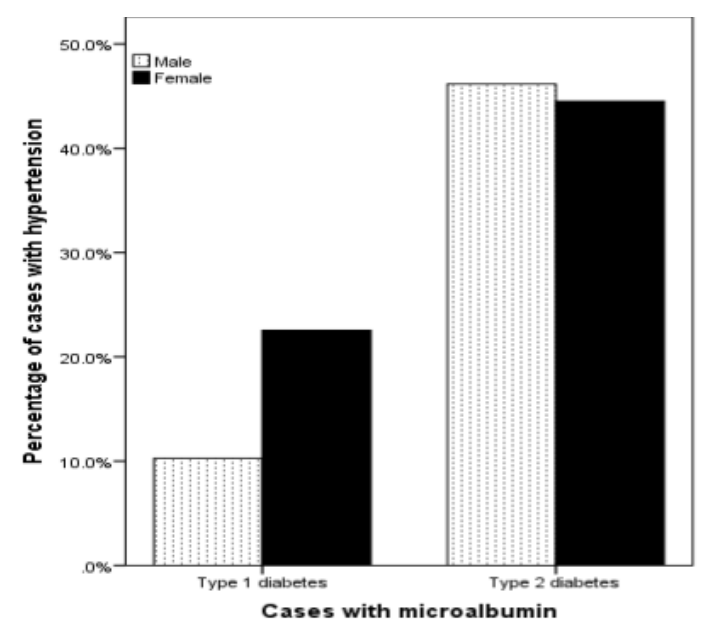

Figure I Frequency of hypertension in cases with type I and type 2 diabetes associated microalbuminuria according to gender

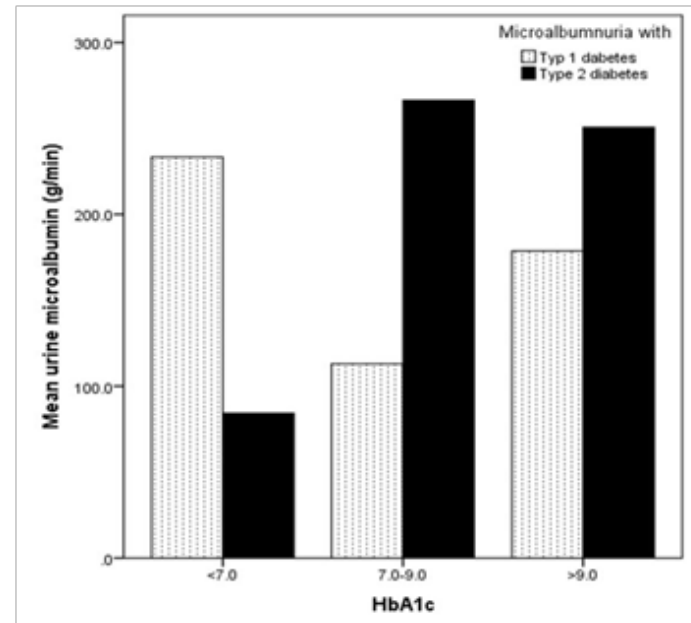

\section{Results}

1416 patients with T2DM and 334 patients with T1DM were screened for MA. Total of 296 patients with diabetes associated MA were included in this study; 99 (33.3\%) with T1DM and 197 (66.6\%) with T2DM. $119(40.2 \%)$ were male and 177 (59.8\%) were female with mean age $35.0 \pm 8.4$, table. Significant female predominance (sex ratio male: female) $1: 2.3$ and 1:1.2 in T1DM+MA and T2DM+MA respectively $(\mathrm{p}=0.01)$. HTN was more frequent in $131(72.0 \%)$ of T2DM+MA compared to $51(28.0 \%)$ of T1DM+MA (p=0.004) with significant difference between both gender, Figure 1. T2DM+MA have significant higher $\mathrm{HbA} 1 \mathrm{c}$ than patients with $\mathrm{T} 1 \mathrm{DM}+\mathrm{MA}$ and there was a nonsignificant difference between gender and when compared to HbA1c groups, Figure 2. Male and Female with T2DM+MA have nonsignificant higher HbA1c $(\geq 7.0)$ than patients with Male and Female with T1DM+MA, Figure 3.

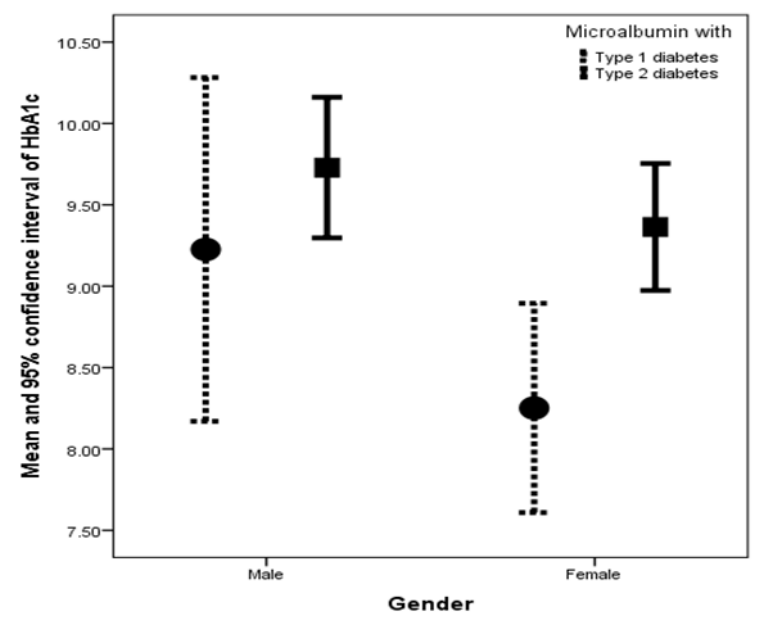

Figure 2 Mean HbAlc in Type I diabetes and type 2 diabetes associated microalbuminuria according to gender

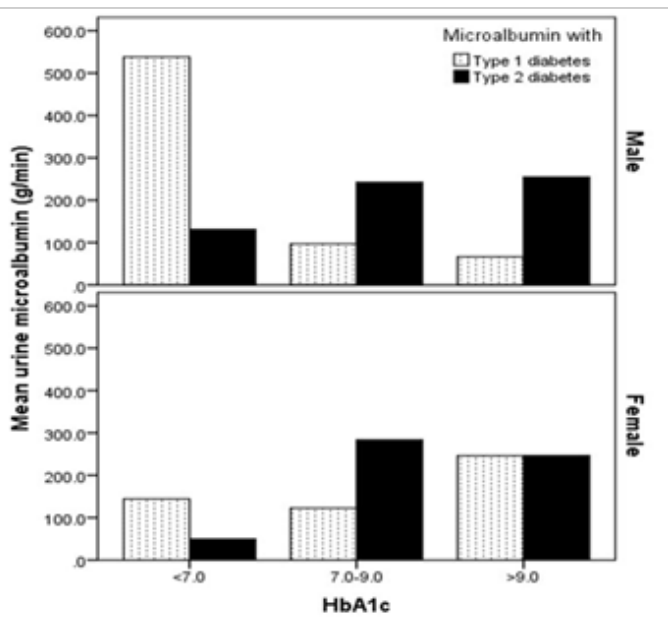

Figure 3 Mean microalbumin in Type I diabetes and type 2 diabetes associated microalbuminuria according to HbAlc groups and gender.

\section{Discussion}

For all health care systems in both developed and developing countries, the chronic diseases represent one of the most difficult challenges, due to their continuous and relentless growth. The care of patients with diabetes contributes significantly to health care costs. DN is the leading cause of end-stage renal disease and of patients with T1DM, $20 \%-30 \%$ will develop DN, whereas about $10 \%-20 \%$ of those with T2DM will do so. ${ }^{27,28}$ There have been in the past couple 
of decades advances in our knowledge regarding the DN, including pharmacological interventions that can significantly slow or even reverse the course of progressive disease.

We have shown in unpublished data that MA frequency in T2DM to be $33.2 \%$. Marked variation in MA prevalence was reported from cross sectional and various epidemiological studies.$^{29-34}$ In Asia, Micro Albuminuria Prevalence Study is a large epidemiological multicentre study to determine the MA prevalence in T2DM patients with hypertension. ${ }^{35}$ They found that $39.8 \%$ have MA in a population of 5,549 patients. This is higher than the prevalence rates reported by us $(33.2 \%)$ and $17 \%$ to $21 \%$ prevalence for Western diabetic patients in

population-based studies. ${ }^{21}$ In another Asian study, in southern India, MA was detected in $36.3 \%$ of T2DM. ${ }^{22}$ The different range in the prevalence of MA in T2DM is likely due to populations differences, in the definitions of MA, urine collection method, genetic and cardiovascular risk factors. Where as we have shown in unpublished data that high frequency of MA in T1DM to be $29.6 \%$. Compared to international rates, this result was far more than reported in many countries worldwide including 5\% in UK, 3.3\% in Germany and $3.3 \%$ in USA. ${ }^{37-38}$ These were comparable to $13.4 \%$ reported in Indian children and $13 \%$ reported in west Australian children with T1DM. ${ }^{39,40} \mathrm{DN}$ patients are a problem at the interface between general medicine, primary care physician, diabetology and nephrology. Thus, possible vascular disease could be indicated by the finding of MA and it is an indication to reduce all cardiovascular risk factors by aggressive intervention. The need for nationwide larger scale studies is important to assess the cost-effectiveness of such frequent and early screening.

The present study showed significant female predominance (sex ratio male:female) $1: 2.3$ and $1: 1.2$ in $\mathrm{T} 1 \mathrm{DM}+\mathrm{MA}$ and $\mathrm{T} 2 \mathrm{DM}+\mathrm{MA}$ respectively $(\mathrm{p}=0.01)$. In discordance with our study, an increased prevalence of MA+T2DM in male compared with female was reported in earlier studies. Some studies in T2DM have revealed male sex as major risk factors for MA ${ }^{31}$ In our study, T2DM+MA and T1DM+MA were more frequent in females and nonsignificantly correlated with younger age $(\mathrm{r}=-0.1, \mathrm{p}=0.3)$ and $(\mathrm{r}=-0.01, \mathrm{p}=0.08)$ respectively in discordance with other studies. ${ }^{33-34}$ Where as female predominance (sex ratio male:female) 1:2.3 was shown in T1DM. Female gender was a risk factor in adolescent patients with T1DM while male gender was found to be a risk factor for DN in adult diabetic patients in studies on German and Swiss children with T1DM. ${ }^{36,40-43}$

Few studies have investigated the association between MA and body mass index. We have also found nonsignificant association of T2DM+MA and T1DM+MA with obesity $(r=0.02, \mathrm{p}=0.8)$ and $(\mathrm{r}=$ $0.07, \mathrm{p}=0.5$ ) respectively in discordance with other studies. In our study, there was significant difference in body mass index between $\mathrm{T} 2 \mathrm{DM}+\mathrm{MA}$ and T1DM+MA patients. This result is in agreement with the result of the study done in Sweden Finland, and Finland while this result was in contrast to studies in Denmark. Insulin resistance is associated with both central obesity and MA..$^{42,44-46}$

Poor glycaemic control is a risk factors for MA. In patients with T2DM, observational studies have reported that poorer glycemic control is associated with the development of MA..$^{31,47-49}$ Glycaemic control has been shown to prevent development of nephropathy and to reverse established pathology. Several prospective, interventional studies showed that a decrease in the development and progression of albuminuria in most cases by improved glycemic control, statistical significance finding was precluded by the small sizes of the cohorts. ${ }^{50,51}$
A meta-analysis study showed intensive therapy significantly reduced the progression of nephropathy risk. $^{52}$ In patients with T1DM, glycemic control is one of the important predictors of the development of MA and poor glycemic control is a well-known risk factor of DN. While tight glycemic control could delay MA, achieving the degree of control by the results of the Diabetes Control and Complications Trial remains impractical. Additionally, there are claims that there is a glycemic threshold below which the risk of progression to MA remains static, and although not confirmed by other reports. ${ }^{53-56}$ In this study, the mean $\mathrm{HbA} 1 \mathrm{C}$ of $\mathrm{T} 2 \mathrm{DM}+\mathrm{MA}$ patients is $9.5 \pm 2.0$ which is significantly higher than that of the T1DM+MA patients, $8.6 \pm 2.5(\mathrm{P}<0.0001)$. Other studies also have concluded that HbA1C is a determinant risk factor for MA, and that poor glycemic control predisposes to MA. ${ }^{31,57-61}$ The finding of a higher mean HbAlc in our T2DM+MA and T1DM+MA patients which supports the fact that MA is, most likely, due to poor glycemic control. Nevertheless, other factors such as genetic and environmental might play a major role in its pathogenesis.

However, as evidenced by available mean $\mathrm{HbA}_{1} \mathrm{c}$ values above $7.0 \%, 57.1 \%$ of T2DM+MA patients as compared to $42.9 \%$ of T1DM+MA patients could not achieve adequate glycaemic control, $\mathrm{p}=0.003 . .^{54}$

We have shown that HTN is significantly more frequent in T2DM+MA compared to T1DM+MA. HTN frequently associated with T2DM in adults. The prevalence of HTN is more than $50 \%$ in patients with T2DM. ${ }^{62} \mathrm{HTN}$ which is often accompanied is itself a risk factor for MA. 1972 was the first to report MA in hypertensive patients without diabetes. ${ }^{22}$ Several studies have shown that MA occurs in about $30 \%$ of patients with hypertension, ranging from $7 \%$ to $40 \%$ depending on age and ethnic group. ${ }^{63,64}$ In T1DM, Various studies have revealed conflicting results, some of these studies showed that HTN especially diastolic pressure is one of important predictors of developing MA while others did not show any significant role of HTN on MA. ${ }^{36,44}$

Many patients with T2DM will require lipid-lowering therapy. However, it is interesting to note that animal studies have shown that high-cholesterol diets worsen renal injury, whereas lowering blood lipids by medications ameliorates the renal injury. Epidemiological studies showed a relationship between hyperlipidemia and DN. A meta-analysis studies in humans concluded that compared with no treatment, treatment was associated with a lower rate of decline in glomeular filtration rate. This effect did not correlate with either the percent change in cholesterol or with the type of lipid-lowering agent. Seven of the trials included only patients with DN. ${ }^{65}$ There were significant associations were also observed with fasting lipid parameters namely total cholesterol and triglyceride. Data from previous cross-sectional studies show that lipids are abnormal in patients with MA and low density lipoprotein are elevated in those at risk of subsequent MA. ${ }^{66,67-70}$ Interestingly, in patients with $\mathrm{T} 2 \mathrm{DM}+\mathrm{MA}$, in concordance with other reports, it is striking that only low density lipoprotein correlates significantly $(\mathrm{r}=0.2, \mathrm{p}=0.02)$.

One of the limitations of this study is that it is a clinic based study. This could have introduced some degree of referral bias. MA detection was based on a single urine spot collection with semi quantitative dipstick determinations. The ADA guidelines acknowledge that this technique has acceptable sensitivity and specificity. Several collections should be done in a 3-6 month period before diagnosing a patient as having MA. ${ }^{5}$ 
We conclude that the frequency of MA in patients with T2DM in this study is high. It is mandatory to have adequate therapeutic and educational resources in addition to competent physicians who can manage MA in diabetic patients by using a continuing, comprehensive and coordinated approach.

\section{Conclusion}

The high frequency of hypertension and poor glycemic control were present in patients with type 2 diabetes complicated with presence of microalbuminuria in this study. It is mandatory to have adequate therapeutic and educational resources in addition to competent physicians who can manage microalbuminuria in diabetic patients by using a continuing, comprehensive and coordinated approach.

\section{Acknowledgments}

None.

\section{Conflict of interest}

The author declares that there is no conflict interest.

\section{References}

1. King RA, Rotter JI, Motulsky AG. The genetic basis of common diseases. Oxford: Oxford Universtity Press. 1992.

2. Fraser FC. Evolution of a palatable multifactorial threshold model. Am $J$ Hum Genet. 1980;32:796-813.

3. Mueller RF, Young ID: Emery's Elements of Medical Genetics. 9th edition.London: Churchill Livingston; 1995.

4. Parving HH: Initiation and progression of diabetic nephropathy. $N$ Engl $J$ Med.1996;335:1682-1683.

5. American Diabetes Association. Microvascular Complications and Foot Care: Standards of Medical Care in Diabetes. Diabetes Care. 2018;41(1):105-118.

6. Mogensen C. Microalbuminuria predicts clinical proteinuria and early mortality in maturity onset diabetes. $N$ Engl J Med. 1984;310:356-360.

7. Dinneen SF, Gerstein HC. The association of microalbuminuria and mortality in non-insulin-dependent diabetes mellitus: a systematic overview of the literature. Arch Intern Med. 1997;157(13):1413-1418.

8. Mattock MB, Barnes DJ, Viberti GC, et al. Microalbuminuria and coronary heart disease in non-insulin-dependent diabetes: an incidence study. Diabetes. 1998;47(11):1786-1792.

9. USRDS Annual Data Report Chapter 2. Incidence and prevalence of ESRD. Am J Kidney Dis. 1999;34:40-50.

10. Pugh JA, Medina RA, Cornell JC, et al. NIDDM is the major cause of diabetic end-stage renal disease: more evidence for a tri-ethnic community. Diabetes. 1995;44:1375-1380.

11. Brancati F, Whelton P, Randall B, et al: Risk of end-stage renal disease in diabetes mellitus: A prospective cohort study of men screened for MRFIT. Multiple Risk Factor Intervention Trial. JAMA. 1997;278:2069-2074

12. Gerstein HC, Mann JF, Yi Q, et al. HOPE Study Investigators: Albuminuria and risk of cardiovascular events, death, and heart failure in diabetic and nondiabetic individuals. JAMA. 2001;286:42-26.

13. Garg JP, Bakris GL. Microalbuminuria: marker of vascular dysfunction, risk factor for cardiovascular disease. Vasc Med. 2005;7:35-43.
14. Adler AI, Stevens RJ, Manley SE, et al. UKPDS Group: Development and progression of nephropathy in type 2 diabetes: the United Kingdom Prospective Diabetes Study (UKPDS 64). Kidney Int. 2003;63:225-232

15. Mogensen CE: Microalbuminuria and hypertension with focus on type 1 and type 2 diabetes. J Intern Med. 2003;254:45- 66.

16. Gæde P, Vedel P, Larsen N, et al. Multifactorial intervention and cardiovascular disease in patients with type 2 diabetes. $N$ Engl J Med. 2003;348:383-393.

17. Basi S, Lewis JB. Microalbuminuria as a target to improve cardiovascular and renal outcomes. Am J Kidney Dis. 2006;47:927-46.

18. McGrath NM, Parker GN, Dawson P. Early presentation of type 2 diabetes mellitus in young New Zealand Maori. Diabetes Res Clin Pract. 1999;43:205-209.

19. Yoo EG, Choi IK, Kim DH. Prevalence of microalbuminuria in young patients with type 1 and type 2 diabetes mellitus. $J$ Pediatr Endocrinol Metab. 2004;17:1423-1427.

20. Fagot-Campagna A, Knowler WC, Pettitt DJ: Type 2 diabetes in Pima Indian children: cardiovascular risk factors at diagnosis and 10 years later (Abstract). Diabetes. 1998;47(1):155.

21. Ettinger LM, Freeman K, DimartinoNardi JR, et al. Microalbuminuria and abnormal ambulatory blood pressure in adolescents with type 2 diabetes mellitus. J Pediatr. 2005;147:67-73.

22. Varghese A, Deepa R, Rema M, et al. Prevalence of microalbuminuria in type 2 diabetes mellitus at a diabetic center in South India. Post-Grad Med. 2001;77:399-402.

23. Parving HH, Osterby R, Ritz E. Diabetic nephropathy. In: BM Brenner, editor. The kidney. WB Saunders, Philadelphia.2000;1731-1773.

24. IDF Diabetes Atlas 7th Edition International Diabetes Federation. 2016.

25. Tuomilehto J, Borch-Johnsen K, Molarius A, et al. Incidence of cardiovascular disease in type 1 (insulin dependent) diabetic subjects with and without diabetic nephropathy in Finland. Diabetologia. 1998;41:784-90.

26. Spooren PF, Lekkerkerker JF, Vermes I. Micral-test: a qualitative dipstick test for micro-albuminuria. Diabetes Res Clin Pract. 1992;18:83-87

27. Whelton PK, Carey RM, Aronow WS, et al. ACC/AHA/AAPA/ABC/ ACPM/AGS/APhA/ASH/ASPC/NMA/PCNA Guideline for the Prevention, Detection, Evaluation, and Management of High Blood Pressure in Adults: A Report of the American College of Cardiology/ American Heart Association Task Force on Clinical Practice Guidelines. $J$ Am Coll Cardiol. 2017;71(6):1269-1324.

28. Andersen AR, Christiansen JS, Andersen JK, et al. Diabetic nephropathy in Type 1 (insulin-dependent) diabetes: an epidemiological study. Diabetologia. 1083;25:496-501.

29. Krolewski AS, Warram JH, Christlieb AR, et al. The changing natural history of nephropathy in type I diabetes. Am J Med.1985;78:785-794.

30. Neil A, Hawkins M, Potok M, et al. A Prospective population-based study of microalbuminuria as a predictor of mortality in NIDDM. Diabetes Care. 1993;7:996-903.

31. Collins VR, Dowse GK, Finch CF, et al. Prevalence and risk factors for micro and macroalbuminuria in diabetic subjects and entire population of Nauru. Diabetes. 1989;38:1602-1610.

32. Gupta DK, Verma LK, Khosla PK, et al. The prevalence of microalbuminuria in diabetes: a study from north India. Diabetes Res Clin Pract. 1991;12:125-128. 
33. Klein R, Klein BEK, Moss SE. Prevalence of microalbuminuria in olderonset-diabetes. Diabetes Care. 1993;16:1325-1329.

34. Allawi J, Rao PV, Gilbert R, et al. Microalbuminuria in noninsulindependent diabetes: its prevalence in Indian compared with Europid patients. Br Med J (Clin Res Ed). 1988;296:462-464.

35. John L, Rao PS, Kanagasabapathy AS. Prevalence of diabetic nephropathy in non insulin dependent diabetes. Indian J Med Res. 1991;94:24-29.

36. Kong $\mathrm{NC}$ et al. Microalbuminuria prevalence study in hypertensive type 2 diabetic patients in Malaysia. Med J Malaysia. 2006;61(4):457-65.

37. Li L, Jick S, Breitenstein S, et al. Prevalence of diabetes and diabetic nephropathy in a large U.S. commercially insured pediatric population, 2002-2013. Diabetes Care. 2016;39:278-284.

38. Holl R, Grabert M, Thon A, et al. Urinary excretion of albumin in adolescents with type 1 diabetes: persistent versus intermittent microalbuminuria and relationship to duration of diabetes, sex and metabolic control. Diabetes Care. 1999;22:1555-1560.

39. Raile K, Galler A, Hofer S, et al. Diabetic nephropathy in 27,805 children, dolescents and adults with Typel diabetes: Effect of diabetes duration, A1C, hypertension,dyslipidemia, diabetes onset and sex. Diabetes Care. 2007;30:2523-2528.

40. Gallego P, Bulsara M, Frazer F, et al. Prevalence and risk factors for microalbuminuria in a population-based sample of children and adolescents with T1DM in Western Australia. Pediatr Diabetes. 2006;7:165-172.

41. Bogdanović R. Diabetic nephropathy in children and adolescents. Pediatr Nephrol. 2008;23:507-525.

42. Tebbe U, Bramlage P, Thoenes M, et al. Prevalence of microalbuminuria and its associated cardiovascular risk:German and Swiss results of the recent global i-search survey. Swiss Med Wkly. 2009;139:473-448

43. Riihimaa PH, Knip M, Hirvela TT, et al. Metabolic characteristics and urine albumin-excretion rate in relation to pubertal maturation in type 1 diabetes. Diabetes Metab Res Rev. 2000;16(4):269-275.

44. Schultz CJ, Konopelska-Bahu T. Microabuminuria prevalence varies with age, sex, and puberty in children with type 1 diabetes; follow up from the diagnosis in a longitudinal study. Diabetes care. 1999;22(3):495-502.

45. Cederholm J, Eliasson B, Nilsson PM, et al. Microalbuminuria and risk factors in type 1 and type 2 diabetic patients. Diabetes Res Clin Pract. 2005;67(3):258-266.

46. Mortenson HB. Practical aspects of managing diabetes in adolescents. Acta pediatr. Suppl. 1998;425(5):72-76.

47. De Boer IH, Sibley SD, Kestenbaum B, et al. Central Obesity, Incident Microalbuminuria, and Change in Creatinine Clearance in the Epidemiology of Diabetes Interventions and Complications Study. $J$ Am Soc Nephrol . 2007;18:235-243.

48. Schmitz A, Vaeth M. Microalbuminuria: a major risk factor in non-insulindependent diabetes: a 1-year follow-up study of 503 patients. Diabet Med. 1987;5:126-134.

49. Haffner SM, Morales PA, Gruber MK, et al. Cardiovascular risk factors in non-insulin dependent diabetic subjects with microalbuminuria. Arterioscler Thromb. 1993;13:205-210.

50. National Kidney Foundation. K/DOQI Clinical Practice Guidelines for Chronic Kidney Disease. Part 5: Evaluation of laboratory measurements for clinical assessment of kidney disease. Am J Kidney Dis. 2002;39:6-92.

51. Schmitz A, Vaeth M. Microalbuminuria: a major risk factor in non-insulindependent diabetes: a 1-year follow-up study of 503 patients. Diabet Med. 1987;5:126-134.
52. Lauritzen T, Frost-Larsen K, Larsen HW, et al. Two-year experience with continuous subcutaneous insulin infusion in relation to retinopathy and neuropathy. Diabetes. 1985;3:74-79.

53. Beck-Nielsen H, Olesen T, Mogensen CE, et al. Effect of near normoglycemia for 5 years on progression of early diabetic retinopathy and renal involvement. Diabetes Res. 1990;15:185-190.

54. Wang PH, Lau J, Chalmers TC. Meta-analysis of effects of intensive blood-glucose control on late complications of type 1 diabetes. Lancet. 1993;341:1306-1309.

55. The Diabetes Control and Complications Trial Research Group: The effect of intensive treatment of diabetes on the development and progression of long-term complications in insulin dependent diabetes mellitus. N Engl J Med.1996;329:977-86.

56. Krolewski AS, Laffel LMB, Krolewski M, et al: Glycosylated hemoglobin and the risk of microalbuminuria in patients withinsulin-dependent diabetes mellitus. $N$ Engl J Med. 1995;332:1251-1255

57. The Diabetes Control and Complications Trial ResearchGroup: The absence of a glycaemic threshold for the developmentof long-termcomplications: The perspective of the diabetes controland complications trial. Diabetes. 1996;45:1289-1298

58. Chaturvedi N, Fuller JH: Glycosylated haemoglobin and therisk of microalbuminuria in insulin dependent diabetes mellitus. $N$ Engl J Med. $1995 ; 333: 940-940$

59. UKPDS 33. Intensive blood glucose control with sulphonylurea or insulin compared with conventional treatment and risk of complications in NIDDM. 1998; 352:837-852

60. Schuttz CJ, Neil HA, Dalton RN, et al. Risk of nephropathy can be detected before the onset of microalbuminuria during the early years after diagnosis of type 1 diabetes. Diabetic care. 2000;23(12):1811-1815.

61. Jones CA, Leese GP, Kerr S, et al. Development and progression of microalbuminuria in a clinic sample of patients with insulin dependent diabetes mellitus. Arch Dis Child. 1998;78(6):518-523.

62. Gorman D, Schett E, Daneman D. The natural history of microalbuminuria in adolescents with type 1 diabetes. J Ped. 1999; 134(3):333-337.

63. Svensson M, Eriksson JW, Dahlquist G. Early glycemic control, age at onset, and development of microvascular complications in childhoodonset type 1 diabetes. Diabetes care. 2004;27:955-962.

64. Al-Hermi BE, Al-Abbasi AM, Rajab MH et al.Diabetic nephropathy in children with type 1 diabetes mellitus in Bahrain. Saudi Med J. 2005; 26(2):294-297.

65. Collado-Mesa F, Colhoun HM, Stevens LK, et al. Prevalence and management of hypertension in type 1 diabetes mellitus in Europe: the EURODIAB IDDM Complications Study. Diab Med. 1999;16:41-48.

66. Douglas E, Busby, Atkins, MD, The detection and measurement of microalbuminuria challenge for clinical chemistry. MLO Med Lab Obs. 2005;37(2):8-9

67. Bianchi S, Bigazzi R, Campese VM. Microalbuminuria in essential hypertension: significance, pathophysiology, and therapeutic implications. Am J Kidney Dis. 1999;34:973-995

68. Fried LF, Orchard TJ, Kasiske BL. Effect of lipid reduction on the progression of renal disease: Ameta-analysis. Kidney Int. 2001;59:260-269.

69. Coonrod BA, Ellis D, Becker DJ, et al. Predictors of microalbuminuria in individuals with IDDM. Diabetes Care. 1993; 16:1376-1383

70. Vannini P, Ciavarella A, Flammini M, et al. Lipid abnormalitiesin insulindependent diabetic patients with albuminuria. Diabetes Care. 1998;7:151- 